AyH THE MERSHON CENTER at The Ohio State University OHIO

\title{
Sam Scheffler
}

Sam Scheffler

Berkeley

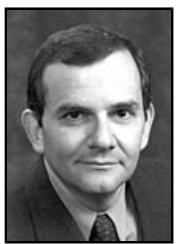

"Is Terrorism Morally Distinctive?"

Monday, May 9, 2005

3:30 p.m.

Mershon Center

Room 120

Samuel Scheffler is the Class of 1941 World War II Memorial Professor of Philosophy and Law at the University of California, Berkeley.

Professor Scheffler received his A.B. from Harvard and his Ph.D. from Princeton. He joined the Berkeley Philosophy Department in 1977, and served as its Chair from 1985 to 1989. Since 1997 he has divided his time evenly between the Philosophy Department and the Jurisprudence and Social Policy Program of the Law School. He works mainly in the areas of moral and political philosophy. He has been a recipient of Guggenheim and NEH Fellowships, as well as a UC President's Research Fellowship in the Humanities and a Visiting Fellowship at All Souls College, Oxford. He is a Fellow of the American Academy of Arts and Sciences. His publications include three books: The Rejection of Consequentialism, Human Morality, and Boundaries and Allegiances, all published by Oxford University Press. He is an Advisory Editor of Philosophy and Public Affairs, and he is Chair of the Advisory Board of the Kadish Center for Morality, Law and Public Affairs. 